\title{
Analysis on Cultivation of Children Inner Music Ability
}

\author{
Liu Lei \\ China West Normal University \\ Nanchong, China \\ 410472661@qq.com
}

\begin{abstract}
Music ability generally starts earlier than other abilities as an innate and natural ability. Therefore, people can obtain music perception ability and strong desire to explore and love music during childhood. People pay more and more attention to cultivating children inner music ability with continuous development of children music education. However, research on cultivating children inner music ability still should be further improved at present. In the paper, cultivation of children inner music ability is adopted as a research object. Main connotations and significance in children inner music ability are deeply explored. Cultivation of children inner music ability is deeply analyzed and discussed from the aspects of 'love', 'respect', 'understanding', 'consciousness', 'communication', 'rhythm sensation', 'painting', etc. Feasible plan is proposed. It is expected that the research can provide certain assistance and reference for cultivating children inner music ability.
\end{abstract}

\section{Keywords-Children; Inner; Music Ability; Cultivation}

\section{INTRODUCTION}

Music ability is innate, natural and the most common ability of children. Children have the ability of 'groaning singing' and 'dancing' during childhood before speaking. It can be said that the innate ability is extremely rare. If such ability can be directed and educated, great effect can be obtained. On the contrary, negative effect can be produced on the whole life of children [1]. Currently, many music teachers have started to pay attention to important significance of cultivating children inner music ability. They actively guide children to participate in music activities at work and strive to organize activities lively and actively with rich education significance. However, current development situation shows that their cultivation on children inner music ability still should be further improved.

Music education is considered to be one of important contents in children artistic quality and music education. Plato, an ancient Greek philosopher, also has pointed out: music can be deepened into the hearts of children, which will not fade forever, people with good music education can identify the beauty and ugliness swiftly, and music education makes people noble and outstanding. Music is art of emotion. It arouses the resonance of the inner mind through voice, and it is the door to open children's wisdom, which is closely related to formation of children's personality and intelligence development with important significance to children's world outlook, values, and children's growth [2-3]. The author adopts cultivation of children inner music ability as research object, and deeply explores its main connotation and significance. Corresponding cultivation plan is formulated. It is expected that the author's research can provide certain assistance and reference for cultivating children inner music ability to certain extent.

\section{CHILDREN'S MUSIC ABILITY}

Music ability refers to ability of perceiving, understanding, expressing and creating music, which can be congenital and acquired through learning. It includes perception and distinguishing ability on music, understanding ability on music relationship, expression and utilization ability on music skills. Own music ability of children is studied in the section [4].

According to current academic research on the cultivation of children music ability, most scholars believe that music perception is genetic completely, which can't be changed. However, research proof at current stage shows that children music ability can be gradually improved in subsequent careful cultivation on the basis of innate heredity, such as ability to distinguishing semitone and modulation. If children can frequently listen to semitone music or accompaniment before 3.5 years old, or they can sing semitone and modulation, such ability will be "fixed" and useful for lifetime. Many scholars believe that if children are lack of such cultivation before 3.5 years old, it is difficult to obtain the ability after seven years old [5-7]. The author believes that the ability of recognize chords is related to subsequent cultivation more closely, but the age requirement can be relaxed.

Music perception ability of children does not simply belong to heredity in fact. Children music perception ability is greatly affected by parents on the basis of previous academic research. For example, children like Beijing Opera if their parents like it [8-9]. Children will learn a variety of singing and performing methods from their parents. Parents' favor on classic music, opera and pop music also affect their children. Parents will show their feeling from expression and words, thereby leading children to enter the realm. It is no wonder that some children can produce a variety of fantasies in music as they are just in the realms. Their facial expression and acts are changed during listening. Children lack of music environment can not appreciate it.

Therefore, education of children music perception ability is established on the basis of such subsequent cultivation in order to make up for a part of defect in family education. Generally speaking, certain achievements also can be obtained in cultivating children inner music ability through school or early education 
groups. However, it is difficult to implement one-to-one teaching, the effect is not desired.

\section{FORMATION OF CHILDREN'S INNER MUSIC}

\section{A. Music Perception Activity is the Foundation of Forming Inner Music}

Inner music image, as main representation form of inner music hearing sense, is also formed by musicians in repeated music perception and experience process. It is intuitive and generalized. Successful inner music image should be consistent with inner music demand and music motive demand of music subjects. It is shaped by multiple stimulation of music and constant enrichment of inner music image. The process is also regarded as formation process of inner hearing music hearing sense. However, music practice activity of musicians is endless. New music perception image can be produced through stimulating brain by music each time. Music perception formed each time can be different due to uncertainty of music art and individual difference of subjects. Correspondingly formed music perception image is also different. Music subjects accumulate rich music perception images, and enrich hearing image of receivers. It is obvious that music image is constantly developed and sublimated in music practical activities [10].

\section{B. Music Imagination, Music Emotion, Music Thinking and Other Psychological Activities jointly Promote Formation of Inner Music Image}

Music practice activity of musicians always penetrates throughout music intellectual and mental activity. Music emotion and music imagination occur in music perception process of musicians. In each music perception process, acoustics stimulates musicians in two different perception forms. One is acquisition of brand-new music perceptual materials, and the other is perception of materials matched with information stored in the brain. The later can quickly participate in a series of psychological activities such as music association, etc., thereby forming or enriching specific inner music image. However, the newly perceived music materials can be stored in brain, thereby laying solid foundation for future music stimulation. These music perceptions can be more and more accumulated with constant and repeated simulations of external acoustics. More perception materials can be accumulated. Inner music image can be formed more easily [11]. The music perceptions are regarded as starting points, and inner music images can be formed through comprehensive functions of inner music activities such as music imagination, music emotion, music thinking, etc. Wherein, music thinking mainly affects inner music image indirectly.

\section{Cultivation and Perfection of Inner Music Image Depend on Personal Diathesis of Musicians and Professional Music Training.}

Music professional basis, personal interest preference, individual character, quality and sentiment culture of musicians have profound influence on their inner music hearing sense. Musician's music creation is adopted as an example. Musician creative motivation triggering and creative idea formation are closely related to aesthetic feeling features, life cognitive tendency, personal culture accomplishment, and emotional pursuit thereof. Musicians are also enlightened by their previous music education, emotional tendency, life concept, and other factors in the process of converting creation impulse into music [12]. These personal accomplishments and professional knowledge are integrated into inner music of musicians. Inner music of musicians can be provided with personality and style. Musician's works can achieve individual character and style.

\section{CULTIVATION OF CHILDREN INNER MUSIC ABILITY}

\section{A. Function of "love" on Cultivating Children Inner Music Ability}

Children inner music ability should be woken up by love. Each child is provided with a window on mind. Their mind window can be closed due to various reasons sometimes due to influence of physical growth. 'Love' is the only key to open mind window. Love is the necessary emotion for music education workers. Love is embodied in all aspects of learning, training, and daily life. Our words and acts have greatly influence on them sometimes. Even a derivative has immeasurable influence on them. Therefore, it is necessary and required to comprehend concrete condition of each child in children music education, thereby comprehending growth process and psychological characteristics of children. Effective music education, training, and guidance can be implemented on them in a targeted mode.

\section{B. Function of "Respect" on Cultivating Children Inner Music Ability}

Secondly, children's self-esteem should be respected. Respect can be used for solving rebellious behaviors of children, and understanding the real thoughts of children. Children are psychologically fragile and sensitive sometimes. They add thick armors on mind in order to prevent hurt, and are prone to aggressive behavior and rebellious psychology. Such feature greatly affects quick acquisition of their music ability. They will be proud and self-esteem will be increased greatly when performance and achievement are obtained [13]. When the self-esteem is damaged or set back at varying degrees, they will show opposition mood and behavior in order to protect selfesteem from damage. Therefore, we should have comprehensive understanding on them, which is embodied in cultivating children music ability.

\section{Function of "Understanding" on Cultivating the Children Inner Music Ability}

Furthermore, we should have sufficient understanding on children. Children's behavior and practices should be understood under the precondition of children's growth. Some deeds are not faults of children, who should not be blamed seriously. Actual teaching in accordance of their aptitude can be achieved if music education workers can realize it. Corresponding music education and guidance can be implemented from practical condition of children. Children's expectation should be responded. Workers should be patient with careful attention, and they should give meticulous care for promoting the growth of children. 


\section{Function of "Consciousness" in Cultivating Children Inner Music Ability}

Orff music teaching requires creating loose and pleasant environment for young children and allowing them to participate in music activities fully so as to improve young children's feeling and expression ability, and promote the all-round development of young children. Music learning is funny firstly for preschool children. If the learning situation and content cannot cause their interest, namely their feeling system cannot be touched, all learning is invalid. Teachers should make abstract rhythm visualized, interesting and lifestyle as much as possible. Funny games should be designed according to young children at different degrees, which should be combined with music, therefore young children can learn easily. All young children can participate in the games and actively cooperate with teachers for completing teaching. Young children should not regard music learning as a burden. Happy atmosphere can cultivate interests of young children in singing, coordinate their action ability, develop their imagination and creativity, and make them to produce desire to learn actively. Children can learn in game, and play game in learning, and their happiness can be shared [14].

\section{E. Function of "Communication" in Cultivating Children Inner Music Ability}

Teachers should communicate with parents for effectively cooperating with music education. Children may experience music education at several stages after birth. Family music education is the most important music education, which is critical for forming children's character and mentality. They will enter school and society subsequently. Therefore, effective cooperation and harmony among family, school and society organization is required for children music education, thereby directing efforts to the same goal. Such care and exchange are particularly important aiming at children in school. However, many parents send children to school and care about nothing in fact. Parents believe that teachers are responsible for the remaining music education, who are busy with work and earning money, and pay limited attention to learning and growth of children. The behavior is not beneficial for children growth. Teachers should timely feedback children's condition at school to parents, and organize parents for propagandizing importance of family music education. Therefore, parents can learn national law in music education and policy about music education teaching, and parents can improve their recognition on children music education. Group children, as citizens, enjoy all basic citizen rights given by Constitution, and basic knowledge of children music education should be taught to parents. Teachers should collect music education information, comprehend problems of parents in family music education, and give timely solution.

\section{F. Function of 'Rhythm Sensation' on Cultivating Children Inner Music Ability}

Cultivation of children inner music rhythm sensation should be consciously strengthened in specific teaching activities. Rhythm is the life of the music and source of music viability. Rhythm sensation is the center of rhythm training. Rhythm sensation refers to an ability of perceiving, comprehending, and correctly expressing note value mutual relationship in music works agilely and quickly. In teaching, inner rhythm sensation of students should be cultivated and trained consciously. 'Stick' should be gradually discarded on the basis of hand tapping and clapping. Rhythm sensation can be converted to intrinsic expression ability on music perception.

\section{G. Function of "Music Sense" on Cultivating Children's Inner Music Ability}

Music sense is the ability to understand music and feel music. It firstly comes from hearing sense of music. Cultural knowledge background expressed by music can be comprehended in the process of listening to music. Many great musicians in music history not only have high music talent, but also belong to knowledgeable scholars. For example, Beethoven is proficient in the ancient Latin, and Schumann and Berlioz have excellent writing ability. These features provide valuable essence for music culture at the romantic period, thereby promoting music development. Culture quality and life knowledge of children also must be improved in order to cultivate inner music ability of children, thereby assisting children to better comprehend excellent music works. Secondly, charm of music should be explained for children. Children can be familiar with and comprehend music works as far as possible, thereby improving their comprehension ability on works. Own emotion can be input into the work on the basis of being familiar with and comprehending the works. Therefore, playing can be successfully converted into own inner music.

\section{H. Function of "Painting" on Cultivating Children Inner Music Ability}

Painting and music should be combined for supplement education. Music is an auditory art, and painting is a visual art. Painting color and image make children to present some corresponding image in mind, which are in line with characteristics of children's concrete image thinking. Therefore, painting means can be flexibly utilized in music activities, visual and hearing methods can be combined visually and intuitively. Children are more willing to listen to music, who can remember the lyrics by painting. When children learn to sing songs, children can sing the lyrics as long as the teacher points at the diagram, thereby quickly learning to sing. Painting teaching is highly expressive, which can attract children's interest of learning music in teaching at the same time. Children are willing to learn music, and implementation objects are formed for education. Therefore, such teaching method can receive better effect.

\section{CONCLUSION}

In summary, teachers should flexibly use various forms such as story, painting, body language, etc. according to age characteristics and psychological characteristics of children in music activities. Therefore, children's mind can be in 'state suitable for being waked up'. Children are guided for learning, focusing on and being willing to listen to music through appropriate environmental stimuli. Therefore, children health development in mind and body can be promoted through music activities. In the paper, 
children inner music ability cultivation is discussed and studied from many aspects of children mentality, communication condition, concrete teaching, etc. It is expected that the paper can provide certain reference and assistance for children music teaching in China.

\section{REFERENCES}

[1] Yang Nan, Zhao Junying. "The cultivation of the music ability of preschool children based on the music theory of Orff," Journal of Jiamusi Education Institute, vol.10, 2012, pp. 221-222.

[2] Ge Qian,Zhou Yong. "Music Education Conducted in the Earlier Time of Children," Journal of Hunan City University, vol. 2, 2010, pp. 17-19.

[3] Luo Lizhi. "On control and regulation of anger mood of primary school music teachers," Hunan Normal University, 2014.

[4] Lei Lei. "Research and discussion on children piano music education teaching method," Journal of Jiamusi Music Education College, vol.6, 2010, pp. 90-93.

[5] John Blacking. Man 'musical. People's Music Publishing House, Beijing, 2007.

[6] Deng Ping. "The Intenpretation of "bi-musicality" and the Student's Training Schedule," Musicology In China, vol.3, 2006, pp. 35-37.
[7] Wu Qiong. "How to cultivate children music understanding ability in piano teaching," Charming China, vol.20,2009, pp. 55-57.

[8] Zhang Shuhui. "Research on factors influencing the development of children's musical ability," Studies in Preschool Education, vol.10, 2006, pp. 16-19.

[9] Xu Lei. "Cultivation of Child's Musical Competence through Listening," Studies in Preschool Education, vol.11, 2007, pp. 51-53.

[10] Chen Jingyi. "Study on music capacity under"dual perspective," Chinese Nursing Research, vol.24, 2014, pp. 2945-2948.

[11] Shi Wei. "Research on the Characteristics of Inner Hearing of Music," Journal of Nanjing Art Institute (Music \& Performance), vol.3, 2007, pp. 29-31.

[12] You Fang. "The Heart Sense of Hearing in Music Performance," Journal of Nanping Teachers College, vol.25, 2006, pp. 137-141.

[13] Yu Xiaoou, Xu Xiaohui. "The Study and Practice Ability of Preschool Music Undergraduate Students Ability," Journal of Educational Institute of Jilin Province, vol.28, 2012, pp. 90-91.

[14] Zhu Jieqiong . "A Brief Discussion on the Cultivation of Students' Inner Sense of Hearing in Vocal Music Learning," The Science Education Article Collects, vol. 5, 2012, pp. 167-168. 